\title{
"Tiene que ser política de Estado". El aporte de las cooperativas de liberados sobre la cuestión carcelaria
}

\author{
"It has to be State policy". The contribution of the former prisoners \\ cooperatives on the prison issue
}

\author{
Malena García malena garcia@live.com \\ https://orcid.org/0000-0002-8758-7080
}

Instituto de Estudios Comunicacionales Aníbal Ford; Facultad de Periodismo y Comunicación

Social; Universidad Nacional de La Plata (Argentina)

\section{Resumen}

El siguiente trabajo aborda las dificultades en la inserción en el mercado laboral formal que atraviesan las personas ex detenidas debido a los antecedentes penales, lo que se configura como una extensión del castigo penal. Estas dificultades explican la conformación de diferentes cooperativas de liberados/as como forma de habilitación de la inclusión social. Se analizará el aporte de estas cooperativas sobre la cuestión carcelaria, entendiendo que se trata de 
experiencias organizativas que exceden el fin del trabajo, buscando institucionalizar el acceso al mismo para los y las liberadas, transformando así sus condiciones de existencia. A su vez, retomamos para el análisis los testimonios de los y las trabajadoras cooperativistas como narrativas de acontecimientos históricos y políticos, entendiéndolos protagonistas de las experiencias que constituyen nuestro objeto de estudio.

Palabras clave: Cárcel; cooperativas de liberados; acceso al trabajo; inclusión social.

\section{Abstract}

The following work addresses the difficulties in the insertion in the formal labor market that former prisoners go through due to criminal records, which is configured as an extension of criminal punishment. These difficulties explain the conformation of different liberated cooperatives as a means of enabling social inclusion. The contribution of these cooperatives on the prison issue will be analyzed, understanding that it is about organizational experiences that exceed the end of work, seeking to institutionalize the access to it for the former prisoners, transforming their conditions of existence. In turn, we return to the analysis the testimonies of the cooperative workers as narratives of historical and political events, understanding them as protagonists of the experiences that constitute our object of study.

Keywords: Prison; former prisoners cooperatives; access to work; social inclusion.

El siguiente informe retoma algunos de los resultados obtenidos a partir de la investigación realizada en el marco de la tesis de grado La salida es colectiva: experiencias organizativas de ex detenidos/as. Dicha investigación se planteó el objetivo de indagar en las prácticas sociales a partir de las cuales las personas que salen de las cárceles bonaerenses buscan reposicionarse en la trama comunitaria, haciendo hincapié en las experiencias organizativas que se generaron en el período reciente como estrategia para habilitar su propia inclusión social.

En una primera parte, analizaremos una dimensión entre los diversos obstáculos que implica el reposicionamiento en la trama comunitaria al salir en libertad: las dificultades para la inserción en el mercado laboral de las y los liberados debido a los antecedentes penales. Luego, abordaremos el aporte de las cooperativas para la transformación de esta problemática. Retomamos para nuestro análisis los testimonios de los y las trabajadoras cooperativistas, 
entendiéndolos como protagonistas de las experiencias que constituyen nuestro objeto de estudio. En este sentido, procuramos privilegiar el lugar político de su enunciación como instrumento metodológico cualitativo. Retomamos las palabras de Hueso, Araña, Mula y Miqui (cooperativa Los Topos), Lupo (cooperativa Las Termitas) y Paulina (cooperativa Las Topas), a partir de entrevistas en profundidad realizadas durante el trabajo de campo comprendido entre los meses de mayo y noviembre de 2018. Recuperamos sus voces, entonces, como narrativas de acontecimientos históricos y políticos (Colanzi, 2015).

\section{La libertad y el encierro a cuestas}

Para comenzar, afirmamos que el encarcelamiento implica el agravamiento de condiciones de vulneración previas al proceso penal sobre las personas que atraviesan el encierro. En este sentido, tanto las trayectorias laborales como educativas de las personas privadas de la libertad son fragmentarias. Al momento de ser detenidos/as, el $41 \%$ estaba desempleado/a, mientras que otro $41 \%$ trabajaba en forma parcial y sólo el $18 \%$ era trabajador/a en tiempo completo (SNEEP, 2016'. Esto constituye un indicador de un problema previo de acceso al trabajo que no se modifica con el paso por la cárcel, ya que el $79 \%$ de las personas detenidas no participa de las capacitaciones laborales y el $48 \%$ no participa de experiencias educativas en contexto de encierro. Al recordar la transición de la cárcel a la calle, Miqui manifestaba:

Cuando salís en libertad, salís en libertad sin nada. Para atrás, con las manos para atrás, sin plata, sin nada, con tu familia... Llegás a tu casa y una semana capaz que aguantás, dos, a la tercera ya querés ir y robar para tener algo. No te queda otra [...] Está bien, vos estás en libertad, está todo bien, una semana está bien, a la otra semana sabés que no tenés leche, no tenés pan, no tenés pañales para tus hijos, ya no te queda otra, tenés que salir a robar, viste. [...] Y después terminás otra vez en la cajita, y terminás otra vez lo mismo: con tu familia sufriendo, con vos en la caja y vuelve a pasar lo mismo hasta que volvés a salir y vuelve a pasar lo mismo... (Miqui, comunicación personal).

Miqui señala una serie de obstáculos al salir en libertad: la carencia de elementos de primera necesidad (leche, pan, pañales) y la urgencia por resolver la situación económica familiar a través de la práctica delictiva exclusivamente ("no queda otra"). Esta sensación de falta de alternativas para la subsistencia más allá del círculo delictivo coincide con los relatos de Araña y Paulina: 
Araña: Cuando salí, si bien sentí una libertad, también sentí... Es otra mochila. Vos te sacás la mochila de estar encerrado, no poder salir, después te subís la mochila de encarar otra vez la calle sin ninguna herramienta. Otra vez robar, decía yo.

Paulina: Mirá, fue una época muy dura. Ahí se ve el contraste con la realidad de la calle. Ahí estás como que bueno, sobrevivís, y después en la calle tenés que sobrevivir igual pero con plata. Y haciendo las cosas bien (Araña y Paulina, comunicación personal).

Los sentidos que sobresalen al relatar el momento de salir en libertad se relacionan con la carga de sobrevivir en la calle sin herramientas, tal como se sobrevivía en la cárcel. A su vez, las prácticas delictivas están presentes entre las posibilidades de sobrevivencia, sea considerándolas ("otra vez robar, decía yo") o descartándolas ("haciendo las cosas bien”). Así, el delito, muchas veces representado en el imaginario social como "la salida fácil" a la situación económica, conlleva una fuerte presión ante la posibilidad de reincidir en el encierro. Estas cuestiones conviven con el reposicionamiento en roles que se ocupaban en la dinámica familiar previa al encierro, lo que constituye otra urgencia para resolver los modos de provisión:

Si yo salgo, no hay laburo, ¿qué tengo que hacer?: chorear. Porque otra no me queda. Ya demasiado que mi familia me bancó toda la condena, salir y que me siga bancando... Viste, vos tenés a tus hijos, tenés [a] tu mujer... Tenés necesidades también, como todo. Si vos no tenés laburo, ¿qué aprendiste a hacer?: [a] chorear (Hueso, comunicación personal).

El testimonio de Hueso resulta interesante para comprender el impacto que tiene la prisionalización sobre las redes comunitarias y familiares. El encierro no sólo provoca la ruptura de los lazos familiares, con el proceso emocional que ello conlleva, sino que los y las familiares deben subsistir con la falta de un sostén económico, y además, sumar un significativo gasto económico a la cotidianidad: los viajes a las cárceles — situación que puede ser más costosa si los detenidos y detenidas son trasladadas a unidades penales lejanas-, y la provisión de bienes básicos. Estos elementos y la violencia institucional ejercida sobre los/as familiares a través de las requisas corporales configuran una extensión del castigo y el control hacia ellos/as (Malacalza, 2012).

Pasa que uno cuando está preso, el tiempo queda en stand by, no ve lo que sucede afuera. Uno está atrapado en una micro-sociedad, que es la cárcel. Pero no se ve el afuera. En la cárcel lunes, martes, miércoles, jueves, son todos los días iguales. Pero uno no tiene, no sabe cuál es el costo de vivir afuera. Si uno cuando ve por televisión, lo que sea, no sabe lo que es ir a un almacén, sacar la billetera y comprar. No lo ve a eso, el esfuerzo que hace la 
familia. Y el problema es cómo ayudar a la familia cuando uno sale (Mula, comunicación personal)

De esta manera, tal como establece el testimonio de Mula, el regreso a la dinámica familiar implica una carga, una presión por asumir nuevamente roles asignados: proveer económicamente, incluso a riesgo de la reincidencia en los penales. En palabras de Viegas Barriga (2012a: 101): "Así como "privado de la libertad" no implica que no se esté privado de muchos otros derechos, tampoco liberado es libertad". Viegas Barriga (2012a) establece que recuperar la libertad ambulatoria no implica que las y los liberados no continúen circulando en redes acotadas producto del estigma territorial y la persecución cultural y policial. Esta imposibilidad de circular en determinados territorios, así como de acceder a redes socio/laborales por fuera de los barrios que habitan, constituyen formas de elastización del castigo. En el caso de esta ponencia, profundizaremos sobre la imposibilidad de inserción en el mercado laboral formal debido a los antecedentes penales como una extensión del castigo. Una vez cumplida la condena, los registros de las sentencias condenatorias forman parte del Registro de Reincidencia durante diez años. En otras palabras, se continúa pagando por un delito cometido incluso después del plazo establecido por la misma Justicia.

\section{Trabajo formal y antecedentes penales}

Abordar los modos en que se da la integración comunitaria después del paso por la cárcel, nos permite vislumbrar que los liberados y liberadas provienen de los sectores más desventajados de la sociedad: a esta precarización de antemano, se suma la degradación difusa de la experiencia en el encierro (Viegas Barriga, 2009). La imposibilidad de acceder a un trabajo formal por los antecedentes penales redunda en una profundización de la exclusión, convirtiendo a los liberados y liberadas en sujetos sobrevulnerados, quienes reciben un castigo desproporcionadamente mayor en relación al delito cometido. Estos obstáculos pueden reconocerse en los siguientes testimonios:

[...] yo conseguí un laburo. Primera vez en mi vida que laburaba, que ganaba como tenía que ganar, todo, aprendí el oficio en una fábrica de herrería. Y cuando [el encargado] se enteró de que yo tenía antecedentes me dio una patada en el culo. Me dijo "va contra mis principios" y me echó. $\mathrm{Y}$ mi mujer estaba embarazada. $\mathrm{Y}$ no conseguía laburo, no conseguía laburo... Hasta que salí a chorear de vuelta. Y así (Hueso, comunicación personal). 


\begin{abstract}
Yo trabajaba en el depósito [de una fábrica de zapatos] y yo soy una persona que le pone mucho empeño al trabajo. $Y$ empecé a trabajar y a trabajar, me empezaron a dar horas extras y empecé a hacer mucho laburo bueno. [...] Y después un día me llamó [el encargado] y me dice "Mirá, ¿puedo hablar con vos? La verdad que estamos todos impresionados, tenés antecedentes, antes de que te lo diga la empresa te lo quiero decir yo, no trabajamos con ese perfil de personas". Quedás afuera del laburo (Araña, comunicación personal).
\end{abstract}

[...] yo cumplía, quería laburar. Cumplía horario y me quedaba un ratito más a veces, no le decía nada al chabón, todo piola. Y a los tres meses me llaman. Que habían visto mi desempeño, que era puntual, te vamos a pasar en blanco. $Y$ ahí yo, fue un sincericidio. Le digo "bueno, gracias, te agradezco, la verdad que me hace bien todo lo que me decís, pero bueno, yo te digo la verdad". Porque él me pedía que traiga un documento, un recibo de gas, luz; el analítico del secundario, que no lo tenía. $Y$ el libre antecedentes, que es un trámite que se hace en el municipio. [...] Y al otro día telegrama de despido, corte no podés entrar en la fábrica (Lupo, comunicación personal).

Las palabras de Hueso, Araña y Lupo permiten vislumbrar la reproducción del estigma —según Goffman (2010), la inhabilitación para una plena aceptación social— de peligrosidad que los demarca como delincuentes, incluso después de haber cumplido una condena penal. La decisión de distintos encargados y empleados de despedir a personas cuando se enteran que tienen antecedentes penales no aparece como una cuestión de reglamentos o estatutos, sino como una cuestión moral ("va contra mis principios", "no trabajamos con ese perfil de personas").

Estas decisiones, a su vez, se inscriben en un contexto político-cultural donde el temor al delito es el temor a algunos tipos de delitos y no a otros. Como afirma Rossana Reguillo (2003: 50), "los miedos son individualmente experimentados, socialmente construidos y culturalmente compartidos". En este marco, una vez en libertad, los antecedentes penales contribuyen a la profundización de la exclusión del mercado laboral. Lejos de ser un simple requisito formal, se trata de una política que se inscribe en un entramado de sentidos estigmatizantes, los cuales habilitan prácticas discriminatorias, represivas y punitivas sobre los/as sujetos/as que transitan o han transitado la cárcel. Esta "cultura de criminalización" (Viegas Barriga, 2012b: 220) se configura sobre múltiples prácticas y discursos que funcionan fundamentalmente en dos sentidos: caracterizar el concepto de delito como sinónimo de delitos cometidos por los sectores populares, por un lado; e invisibilizar los procesos de vulneración social por el otro. 
Este estigma también puede reconocerse en la tensión que implica para los liberados y las liberadas el desenvolvimiento en el ámbito del trabajo y la reproducción de prácticas socializantes propias de la cárcel:

\begin{abstract}
Después que me pasó en Jumbo dije "me va a pasar en todos lados". Voy a rendir, van a pasar los tres meses, me van a querer poner en blanco. Y por ahí se me escapaba un berretín de en cana, no sé, por ahí se te escapa algo, encima que salgo hace poco. La gente te cataloga: éste habla como un preso. Éste mira con los ojos con violencia. O éste es esto. $Y$ cada vez que iba me saltaban por distintas cosas, y pasé más o menos por once laburos en blanco (Araña, comunicación personal).
\end{abstract}

Cabe destacar que en los casos analizados, los liberados lograron acceder a distintos trabajos formales, resolviendo una de las dificultades más acentuadas al momento de salir en libertad: la supervivencia económica. Luego, esas posibilidades se veían frustradas cuando, de una u otra manera, eran despedidos al conocerse su condición de ex detenidos. Esta situación, en la mayoría de los casos, los llevó a las prácticas delictivas como única alternativa para obtener un ingreso económico, y por ende, al riesgo de volver a la cárcel. Así, Hueso, Lupo y Araña reincidieron por lo menos una vez en el encierro. En el caso de Paulina no fue así, ya que trabajó de manera informal en el área de control y calidad de una empresa de indumentaria para niños y niñas. Si bien la condición de trabajo en negro implicó que no se conozcan sus antecedentes penales, afirma que en la búsqueda de trabajo formal se sentía señalada:

\footnotetext{
Y, la gente sí te discrimina. Sí que te discrimina. Eso es mentira, o sea, hoy por hoy está como todo más abierto. Pero sí, la gente sí. Vos para buscar laburo te piden ahora al toque el papel de antecedentes. ¿Y qué hacés si tenés antecedentes y querés laburar? Te dicen que no (Paulina, comunicación personal).
}

Durante la investigación realizada constatamos que la concepción predominante en la legislación penal relaciona las causas del delito "con las características individuales del sujeto, presuponiendo que las fallas en su socialización explican la conducta delictiva” (Pocai, 2014: 108). De esta forma, las políticas de seguridad de la provincia de Buenos Aires apuntan a una prevención basada en la represión y vigilancia, en lugar de abordar la problemática del delito a partir de políticas preventivas centradas en la inclusión social (Pocai, 2014). Así, observamos que en los casos que estudiamos, la mayoría de las veces la relación de las y los ex detenidos con el Patronato de Liberados se limitó a firmar una vez por mes una planilla de presentación, 
por falta de información sobre los programas del organismo o por definición ante el tiempo que pasa entre la solicitud hasta la adjudicación del subsidio.

La desfinanciación y precarización de las instituciones encargadas de la integración comunitaria de las personas ex detenidas redunda en la incapacidad estatal de abarcar la problemática. A modo de ejemplo, puede mencionarse el hecho de que el Patronato de Liberados bonaerense cuenta con un personal de alrededor de 1500 trabajadores y trabajadoras en la provincia para cubrir tareas de control, asistencia y tratamiento de 42.457 personas tuteladas (http://www.plb.gba.gov.ar/). Por otra parte, la ley provincial 14.301 establece un cupo del $2 \%$ en la administración pública para liberados y liberadas que hayan cumplido más de cinco años de privación de la libertad, aunque en sus fundamentos establece que la adhesión de los municipios no es obligatoria. Esto implica que los y las ex detenidas se inserten en un contexto de exclusión social que, si bien precede el proceso penal, se recrudece con los antecedentes penales y la falta de implementación de políticas públicas para el sector. De esta manera, la intervención ineficaz de los organismos encargados de la "reinserción" social de los liberados y de evitar su reincidencia, tiene como consecuencia el aumento de probabilidades de retorno a prácticas delictivas y, por ende, de reincidencia en el encierro. En este marco, la situación de salir a robar es leída por Lupo como un acto de rebeldía contra las condiciones insalubres de vida:

\begin{abstract}
Porque vos sentís que la gente, no todos, porque nunca hay que generalizar... Siempre está en ese lugar, como de juzgar. $Y$ no pensar que en realidad hay todo una historia y venimos todos de cosas re fuertes, que llegamos a esa instancia de sacarle a alguien algo material, que es un acto re violento también, pero porque también venimos violentados de la cuna en algunos casos. Cómo queremos que hagamos, que seamos siempre sumisos y aceptemos vivir en una casita de chapa, no tener cloacas, que tu hermanito se cague muriendo porque no había atención médica, que no tengas para morfar, que la policía te cague a palos porque le pinta (Lupo, comunicación personal).
\end{abstract}

De esta manera, el delito aparece como una práctica social en un contexto de vulneraciones, en articulación compleja con los sentidos que los protagonistas le otorgan a esta condición de vulneración y los modos en que estos sentidos se procesan en los sistemas de vinculación social (Míguez, 2008). Intentamos avanzar más allá de la discusión sobre los grados de elección racional en las prácticas delictivas, y por ello diremos simplemente que se trata de prácticas condicionadas socialmente. Ante todo, es necesario aclarar que cuando analizamos las prácticas delictivas en este trabajo, establecemos un recorte arbitrario, puesto que el delito no es propio de un solo sector social (Ídem), sino que tanto las clases medias y altas como 
los/as funcionarios/as públicos/as cometen diversos delitos cotidianamente. No obstante, los delitos con mayor presencia mediática son los cometidos por grupos juveniles poco organizados (Kessler, 2010).

Es fundamental señalar la representación del delito en los medios de comunicación para comprender su impacto social, ya que ésta "impacta en la agenda de preocupaciones, orienta las acciones públicas y contribuye a las sensibilidades de la época” (Kessler, 2010: 5). Así, las políticas públicas dirigidas a la problemática apuntan a perseguir y encarcelar a los jóvenes provenientes de sectores populares, quienes conforman la inmensa mayoría de la población penitenciaria. Como afirma Viegas Barriga (2012b), esta situación muestra una doble instancia de injusticia: por un lado, se invisibilizan los mecanismos políticos y económicos que producen la pauperización y desigualdad social, profundizando las brechas sociales entre los sectores ricos (cada vez más ricos) y los sectores pobres, cada vez más vulnerados. A esto "se suma el hecho de culpabilizar a los sectores más pobres de los males cotidianos, en tanto estos males se traducen prioritariamente como la inseguridad" (Viegas Barriga, 2012b: 234).

\footnotetext{
Hay toda una historia atrás que tiene que ver con eso, con un montón de carencias, de desigualdades. Un montón de cosas que te llevan a tomar una decisión de ir a robar porque estás como al límite entre la vida y la muerte a veces. Que después también puede ser que se transforme en un hábito, que lo naturalices, que uno piense que es un trabajo. Eso es otro tema. Pero cuando vos empezás con el choreo es porque estás... [...] es como que ya se agotaron todos los lugares de contención. Entonces terminás en esa (Lupo, comunicación personal).
} 


\section{El cooperativismo como alternativa de inclusión para los y las liberadas}

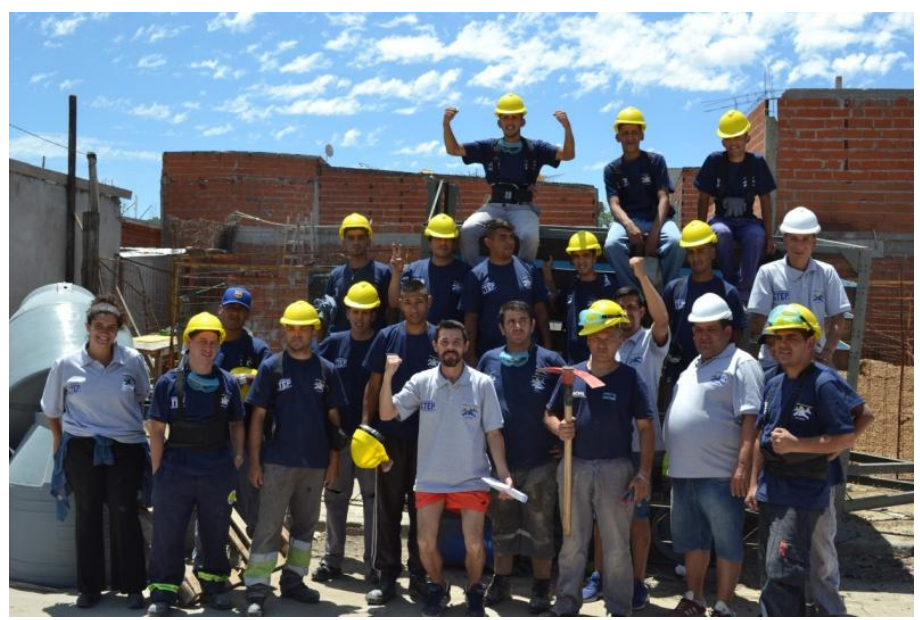

Figura 1. Trabajadores de la cooperativa Los Topos. Barrio Derqui, Caseros. Fotografía: Malena García

La cooperativa Los Topos se formó a partir de un grupo de jóvenes con antecedentes penales que comenzó a hacer trabajos de albañilería en el barrio Derqui de Caseros. La formalización de este trabajo en el marco cooperativo les permitió ampliar los trabajos de obra pública a canchas de fútbol, plazas, instalación de cloacas y conexión de agua potable; lo que les permitió aumentar la cantidad de puestos de trabajo. Los testimonios de Araña y Hueso, que citamos a continuación, remarcan que la cooperativa no surgió como una elección entre distintos tipos de asociaciones productivas, sino a partir de una necesidad concreta, encausando una organización de liberados que ya existía previamente. Además, se representa como una decisión entre alternativas acotadas:

En realidad no lo hicimos porque el cooperativismo nos copaba, ahora sí nos copa porque no lo conocíamos, lo hicimos porque era la única herramienta que teníamos para conseguir trabajo. Nos juntamos ocho pibes de un barrio de provincia con las particularidades que tenemos toda la gente de provincia de los barrios más pobres, que es que la mayoría estuvimos en cana desde chicos, y que sufrimos primero el sistema penal juvenil y después el sistema carcelario para los mayores. [...] Los que llegamos vivos. Hay todo un porcentaje que no llegó porque está muerto y eran dos caminos: o generábamos nuestro propio laburo o seguíamos laburando de lo que habíamos laburado toda la vida, que era con un caño. No queríamos estar más presos y tampoco queríamos morir, entonces decidimos organizarnos esta vez pero para generar laburo para nosotros (Araña, comunicación personal). 
La cooperativa se armó primero por una necesidad. [...] Somos todos pibes con antecedentes que estuvimos en cana y nadie te da una oportunidad. Cuando vos tenés antecedentes, lo primero que dicen es que vos sos chorro. [...] Y cansados de eso, cada vez más pibes presos, más pibes que se iban a la droga, más pibes que volvían a chorear. [...] Para salvar los pibes de la calle, de la delincuencia, de la droga, y empezamos así. Arrancamos los cuatro, después fuimos ocho, y hoy casi somos cien personas en general (Hueso, comunicación personal).

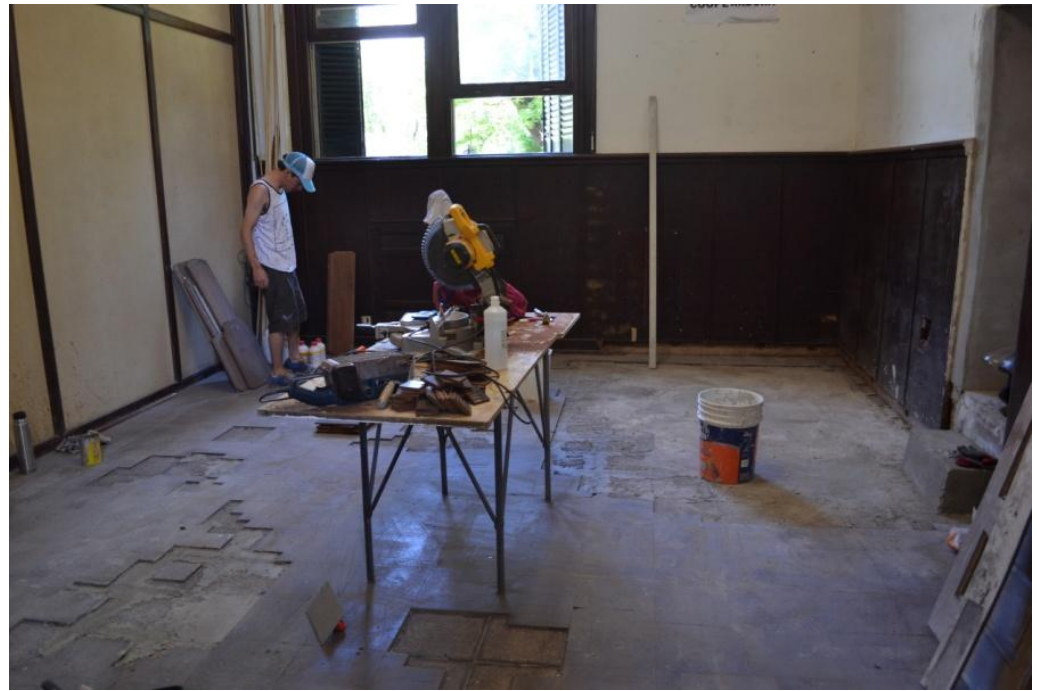

Figura 2. Lupo en un aula en restauración a cargo de la cooperativa Las Termitas. Colegio Nacional, La Plata. Fotografía: Malena García

En 2014, Lupo, uno de los hermanos de Araña, salió en libertad y se mudó a La Plata para continuar cursando el Profesorado en Sociología que había comenzado en la cárcel. A partir de la experiencia de Los Topos, a principios de 2017 se conformó la cooperativa de carpintería Las Termitas en el barrio platense de Los Hornos, por iniciativa de Lupo y otros liberados. Actualmente son cinco integrantes que realizan tareas de refacción en espacios institucionales de la UNLP, como el Colegio Nacional de La Plata, mientras continúan sus estudios en dicha universidad. 


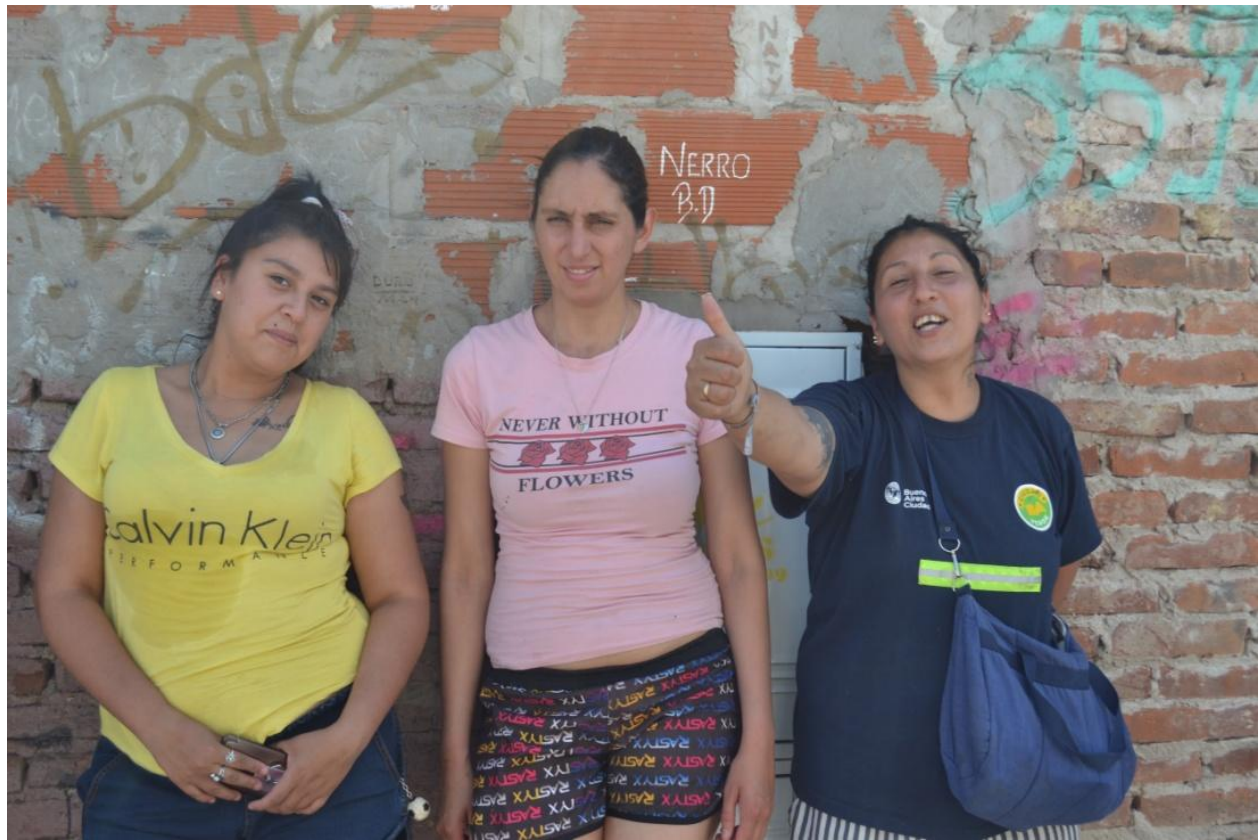

Figura 3. Marianela, Sabrina y Paulina, trabajadoras de la cooperativa Las Topas. Barrio Derqui, Caseros. Fotografía: Malena García

En el caso de Las Topas, la cooperativa se formó en 2017 por iniciativa de Los Topos y un grupo de mujeres del barrio Derqui, entre las cuales se encontraba Paulina. El hecho de que las mujeres que habían estado en la cárcel no se vieran contenidas en el trabajo de construcción por falta de formación para el oficio, derivó en la definición de apostar por un nuevo espacio cuya actividad fuera el reciclado, que incluyera a las liberadas. No obstante, no todas las trabajadoras que integran la cooperativa son ex detenidas, sino que también se incorporaron al proyecto muchas mujeres que se encontraban en una situación de desempleo.

Por otra parte, el crecimiento del trabajo de la cooperativa Los Topos trajo aparejado un aumento de la inserción en las problemáticas del barrio Derqui. Además de sostener el trabajo en los obradores, la cooperativa comenzó un trabajo comunitario que consistía en organizar y brindar una copa de leche para los hijos e hijas de los trabajadores. A este trabajo se le sumó el mantenimiento de una olla popular que, más tarde, derivó en la creación de un comedor en el barrio. Los Topos construyeron una cancha de fútbol y se formó el Club Social Barrio Derqui, donde se realizan jornadas de deporte, murgas y salidas culturales destinadas a niños, niñas y jóvenes del barrio. A partir de este trabajo social, la cooperativa entabló una relación con el Movimiento de Trabajadores Excluidos (MTE) de Tres de Febrero, con el fin de trabajar en conjunto en pos del crecimiento del trabajo comunitario. Esta relación permitió la incorporación 
de las cooperativas Los Topos, Las Topas y Las Termitas a la Confederación de Trabajadores de la Economía Popular (CTEP).

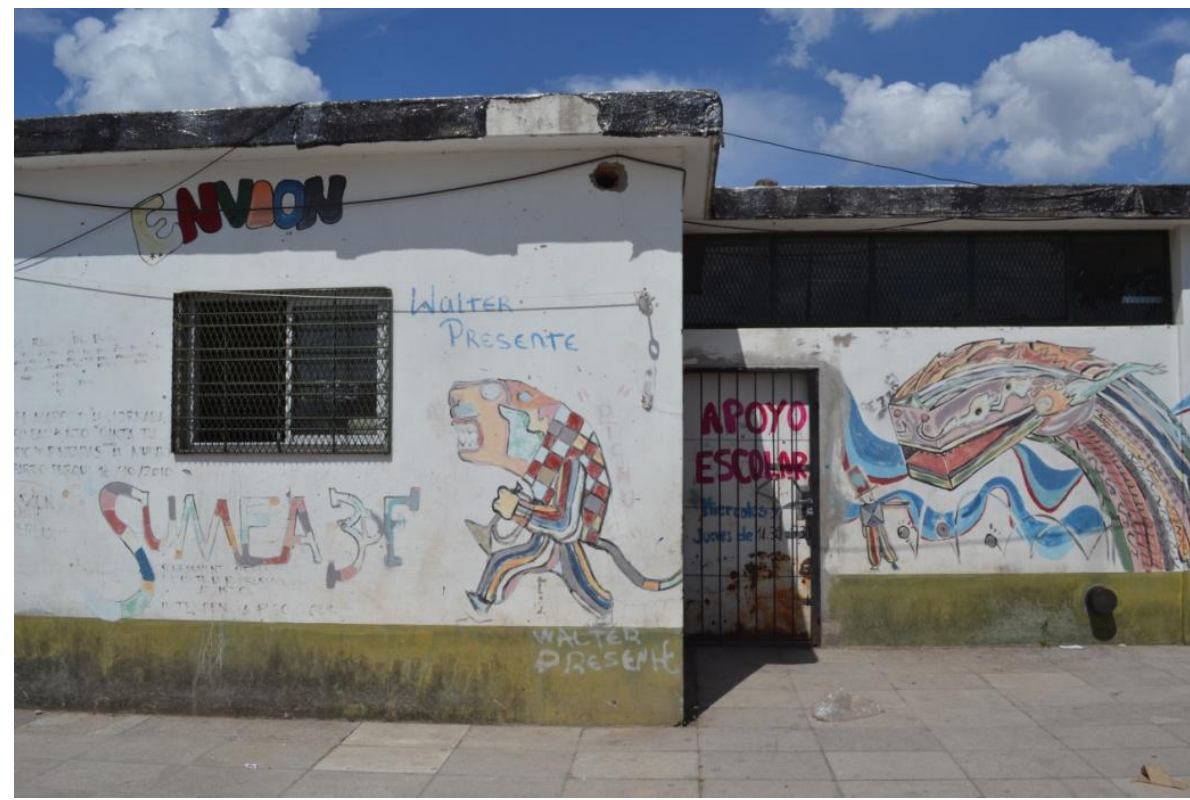

Figura 4. Comedor en el barrio Derqui, Caseros. Fotografía: Malena García

Esta definición implicó la apropiación de una nueva herramienta política. Por un lado, las prácticas de la cooperativa se vieron modificadas por el ingreso a un sindicato, y por ende, a dinámicas políticas de información, formación, representación y articulación con el Estado a través del diálogo, la negociación y el conflicto, entre otras. A partir de su integración en la CTEP, los y las trabajadoras de las cooperativas pudieron acceder a una obra social (gestionada a partir de la Mutual Senderos), al Salario Social Complementario (1), uniformes, herramientas de trabajo y recursos para el comedor. Además, esta incorporación implicó la adscripción a la construcción identitaria de los trabajadores y trabajadoras que propone la CTEP, ya no como precarizados y precarizadas sino como excluidos y excluidas del mercado laboral.

Nosotros nos pudimos expandir a otros barrios porque recibimos el apoyo del MTE, de la CTEP y nadie más. Porque en realidad los convenios que firmamos de trabajo con el Estado se dan porque la CTEP nos hace que nuestro grito que no lo escucha nadie, llegue a la mesa del Estado [...] Y después nos dábamos cuenta que nosotros también somos parte de esos excluidos de que ellos hablan, de la economía popular, de la parte más baja de la sociedad que genera una rueda de dinero que también es la economía y que nosotros 
estamos haciendo mover esa rueda todos los días. Los cartoneros, los recicladores, los vendedores ambulantes, los quinteros. $Y$ ahora nosotros, la gente de las cooperativas de los barrios que no son tenidas en cuenta. Que estábamos en las esquinas, nosotros somos parte ahora de la economía popular (Araña, comunicación personal).

Siguiendo el esquema clásico de división del trabajo por rama de actividad, las cooperativas debían integrarse a las ramas de producción de la CTEP (como las ramas de construcción o cartoneros), lo que dejaba por fuera la discusión específica sobre el paso por la cárcel y las problemáticas que se enfrentan una vez en libertad. Esta situación derivó en una discusión hacia el interior del gremio, que se resolvió con la creación de la rama de liberados y liberadas (MTE-CTEP) y la Secretaría de Ex Detenidos/as y Familiares (SEDyF) de la CTEP. Esta secretaría es integrada por trabajadores y trabajadoras de las cooperativas de liberados y liberadas, excediendo el tipo de producción concreto de cada cooperativa. Juan Grabois, referente de la CTEP, señala algunas de las tensiones presentes en el proceso:

\begin{abstract}
Yo al principio, te soy franco, pensaba que no era bueno eso. Que no era bueno referenciar a las cooperativas y a los trabajadores como parte de un colectivo específico, que el neoliberalismo y la posmodernidad trajo la fragmentación de la clase trabajadora como una estrategia de división. Entonces hay colectivos de lo que se te pueda ocurrir. $Y$ eso genera una cantidad de divisiones y de atomizaciones que hacen que la fuerza del reclamo sea imposible, y además por otro lado, desde la perspectiva de la cultura masiva dominante, la fuerza política de un sector que se referencia como liberado, que es lo mismo que decir ex preso, tiene un estigma encima que va a tardar mucho en resolverse, que puede atentar contra la agenda reivindicativa. Pero después de la discusión con los compañeros, y ver que hay una especificidad muy fuerte en el laburo, que hay una necesidad de que los referentes de las cooperativas de trabajo puedan también entrar en las discusiones específicas vinculadas a lo que pasa adentro de los penales, lo que pasa en los procesos llamados de reinserción, y fundamentalmente por la posición mayoritaria de los compañeros y compañeras, finalmente la opción es desarrollar la rama dentro de lo que es liberados (Grabois, comunicación personal).
\end{abstract}

Grabois señala dos puntos de discusión en la creación de una rama de liberados y liberadas dentro de la CTEP. La primera se relaciona con la fragmentación del colectivo de trabajadores y trabajadoras de la economía popular a partir de múltiples atravesamientos identitarios posibles - como puede serlo, por ejemplo, la condición de inmigrantes en las ramas de campesinos o manteros-, bajo la hipótesis de que la atomización de las diversas identidades supone un debilitamiento de las reivindicaciones del sector. A su vez, indica que las 
reivindicaciones también pueden verse afectadas por el estigma que configura la condición particular de ex detenidos y detenidas. Por otra parte, Daniela, responsable social de la cooperativa Los Topos, aporta otra visión sobre la construcción de una rama particular de liberados y liberadas:

[...] hay mucha discusión en torno a por qué nos hacemos gueto. [...] "El 70, 80\% de personas que están en cooperativas cartoneras atravesaron la cárcel y sin embargo no se construyen como sujeto liberado". Está buena esa discusión. A mí me parece que lo que hacen Los Topos, de poder extenderse como eslabones de la salida y la calle, tipo salís y ya tenés un lugar, tenés tu contención, tenés un trabajo [...] eso es el objetivo para mí de construirse como sujeto liberado. Poder pensarse en relación entre la cárcel y la calle. Poder pensar ese núcleo en el medio, poder pensar en contener eso. Poder pensar que el trabajo tiene que estar organizado pensando en lo que pasa cuando salís de la cárcel. Y también para mí tiene que ver con cómo te involucrás en la vida de esas personas (Daniela, comunicación personal).

En efecto, Rossana Reguillo (1994) coincide en que los nuevos movimientos sociales emergentes en América Latina emprenden luchas simbólicas fragmentadas y parciales. Estos movimientos no sólo se vinculan de manera diferente con el Estado, sino que se agrupan en torno a problemáticas que no pueden ser reducidas a las determinaciones de clase. Si bien el interlocutor fundamental de la SEDyF y la rama de liberados es el Estado, la organización se desvincula de las formas de la toma de poder estatal, sin que eso implique reducir la importancia del mismo. Así, en este escenario los nuevos movimientos sociales ya no descansan en el Estado como la resolución de todas las necesidades sociales sino que "nos enfrentamos a una sociedad civil cada vez más pujante que toma en sus manos la iniciativa, alterando las bases mismas de su relación con el Estado" (Reguillo, 1994: 102). De esta forma, las organizaciones de la sociedad civil se vinculan con el Estado a través de las demandas y reivindicaciones, aunque también construyen y transforman sus territorios superponiéndose con el rol del Estado o inclusive, en algunas ocasiones suplantándolo (Acotto, 2003). La construcción de hegemonía en estos nuevos movimientos, entonces, intenta transformar las visiones dominantes sobre ciertos aspectos de la realidad que los afectan, proponiendo otros elementos en torno a los cuales construir nuevos consensos: "los diversos grupos sociales no se plantean ya la estrategia totalizadora que subvierte o invierte el orden social, se trata más bien de microdisidencias comunitarias, en las que caben distintas respuestas, actitudes frente al poder" (Reguillo, 1994: 102). Asimismo, Reguillo advierte sobre el impacto social reducido 
que resulta de estas acciones. No obstante, "la transformación de las ideas y prácticas que organizan la vida social, requieren de tiempos largos" (Ibídem: 103).

En este marco, la apuesta por la conformación de un espacio que aglutine a las cooperativas conformadas desde la necesidad de trabajo genuino por parte de trabajadores y trabajadoras con antecedentes penales, comporta una novedad en las formas de interacción y en sus maneras de representarse en el mundo. Se trata de la construcción de subjetividades emancipadoras (Reguillo, 1994), en el sentido de que conformarse como grupo a partir de la identificación con el paso por la cárcel visibiliza una problemática social, que deviene transformadora no sólo de sus propias realidades sino de la de otros y otras.

Las cooperativas que tomamos para nuestro análisis forman parte de un colectivo de liberados y liberadas que se gestó en la última década con el objetivo de incluir socialmente a los y las ex detenidas a partir del trabajo y el cooperativismo. Estas cooperativas no sólo mantienen sus espacios cotidianos de trabajo, sino que se agrupan en espacios de tomas de decisiones como la SEDyF y la rama de liberados - con el fin de incidir en determinadas políticas públicas destinadas al sector (existentes o por existir), lo que las lleva a establecer relaciones con actores como el Patronato de Liberados y el Ministerio de Desarrollo Social de la Provincia de Buenos Aires. Estas relaciones, a su vez, producen nuevos sentidos y movimientos subjetivos en la identidad de los y las trabajadoras liberadas; reconociéndose a sí mismos desde múltiples atravesamientos. La indagación sobre estas experiencias nos permite identificar un compromiso social con la problemática alrededor de la cuestión carcelaria, es decir, con la realidad de otras y otros liberados, así como con las problemáticas específicas en las que interviene cada cooperativa. A su vez, las formas de auto-reconocimiento y las narrativas sobre la propia historia son constitutivas de la identidad. Este proceso le confiere sentidos al grupo social, generando pautas y valores sociales a los que adscribir, y así, sentidos de pertenencia.

Es como que uno se lo pone más en la piel, me parece. Porque uno quiere luchar para lograr lo que uno quiere. Si vos laburás en una empresa, laburás tantas horas y te vas a tu casa y bueno. Es problema de tu jefe, me entendés. En cambio acá es como que sí o sí tenemos que tirar todas para el mismo lado. Y ganar el propósito de que tenemos que recolectar tanto para tener tanto, y ganar tanto. [...] Es como que uno se lo siente más (Paulina, comunicación personal.

Estamos agarrando una parte de la población que nadie le da pelota, nadie nada, y darle un laburo a esas personas es un trabajo social también. $Y$ construirlo como trabajador, sin ni siquiera que haya pasado por un taller de oficio, por nada, también es un trabajo social que estamos encarando nosotros (Araña, comunicación personal).

Question, Vol. 1, N. ${ }^{\circ}$ 63, julio-septiembre 2019. ISSN 1669-6581

Instituto de Investigaciones en Comunicación | Facultad de Periodismo y Comunicación Social | Universidad Nacional de La Plata La Plata | Buenos Aires | Argentina

Página 16 de 20 
Esta obra está bajo una Licencia Creative Commons Atribución-NoComercial-Compartirlgual 4.0 Internacional

Malena García "Tiene que ser política de Estado". El aporte de las cooperativas de liberados sobre la cuestión

carcelaria

Al describir la forma de organización cooperativa, Paulina y Araña señalan que se trata de impulsos colectivos para dar respuestas a sus necesidades sociales y económicas ("luchar por lo que uno quiere", "un trabajo social"). Las cooperativas, como organizaciones de la sociedad civil, contribuyen al ejercicio de ciudadanía ya que construyen vínculos comunitarios que favorecen la participación social para alcanzar objetivos comunes, dinamizando procesos de transformación de la realidad desde sus protagonistas (Acotto, 2003).

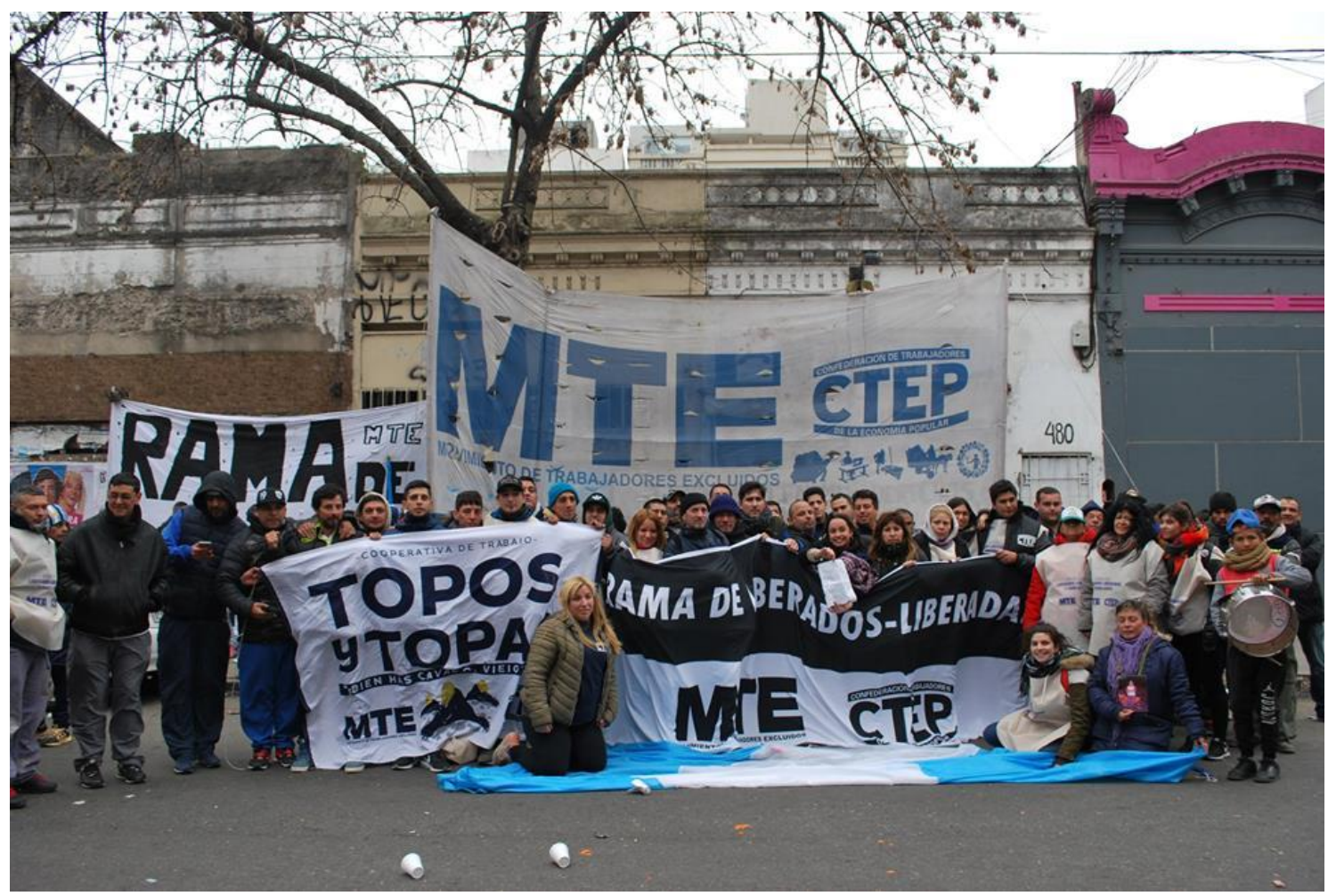

Figura 4. Rama de liberados y liberadas de la CTEP en una movilización a la Secretaría de Derechos Humanos de la provincia de Buenos Aires, exigiendo la implementación de políticas de reinserción laboral para los y las ex detenidas.

17 de julio de 2018. Fuente: www.facebook.com/ CTEP.SEDyF/

Los casos analizados nos permiten afirmar que las cooperativas de liberados y liberadas construyen acciones alrededor de la problemática carcelaria. Su principal prioridad es el acceso al trabajo, por lo que se desprenden acciones para generar y mantener puestos laborales, fundamentalmente a través de la SEDyF, así como para la contención de los y las trabajadoras que se integran a las cooperativas. Sin embargo, la organización excede el fin del trabajo y se amplía hacia otras problemáticas relacionadas con la salida en libertad —las adicciones, la violencia machista, la problemática habitacional, entre otras-, promoviendo debates públicos

Question, Vol. 1, N. 63, julio-septiembre 2019. ISSN 1669-6581

Instituto de Investigaciones en Comunicación | Facultad de Periodismo y Comunicación Social | Universidad Nacional de La Plata La Plata | Buenos Aires | Argentina

Página 17 de 20 
acerca de las trayectorias de vida de las personas que atraviesan la cárcel, teniendo como principal interlocutor al Estado en pos de fomentar políticas pospenitenciarias.

Así, se observan determinadas prácticas como la autodenominación como liberados y liberadas, la decisión de dar a conocer el trabajo de las cooperativas en los medios de comunicación y las movilizaciones pública hacia organismos estatales, como la Secretaría de Derechos Humanos bonaerense. A partir de la sensibilización de actores clave relacionados con la problemática, las cooperativas abrieron una disputa en relación a la necesidad de trabajar lo específico de la cuestión carcelaria en un gremio estratégico, ampliando sus marcos de alianza y fortaleciendo el espacio con la convocatoria a otros espacios organizativos de liberados y familiares de detenidos. Es posible afirmar que estas experiencias organizativas tienen vocación de incidencia política, por lo que apuntan a fortalecer sus capacidades para lograr la participación en el espacio público y en el ámbito de las políticas públicas como horizonte para transformar la realidad de los liberados:

[...] nunca se hicieron políticas de Estado para la gente cuando sale en libertad, y las que se hicieron son nulas o fracasan, o no están, no van a concordarse con la realidad del ser humano que sale. Todas estas experiencias laborales para nosotros [...] salieron de nosotros por no tener oportunidad de vida. [...] Por qué Los Topos hoy en día se pudo desarrollar tanto: porque nosotros siempre pedimos laburo. Nunca nos fuimos a sentar con el Estado, con alguien a decirle "no, nosotros necesitamos una camioneta para que los chicos viajen". Algún día vamos a necesitar diez camionetas, pero primero necesitamos trabajo. No queremos un subsidio [...] nosotros no queremos plata, que nos den plata. Esto se tiene que desarrollar con trabajo, con trabajo genuino. [...] Haciéndonos cargo, nosotros que pertenecemos a una clase de la sociedad que es invisibilizada. Que nos reunimos, que nos juntamos, que nos apoyamos en el gremio de la economía popular. [...] Que nosotros somos la base para que esto entre en la agenda del Estado. Que si nosotros nos conformamos con todo así manualmente [...] y nosotros no nos enfocamos en que esto tiene que ser política de Estado... Que el día de mañana nosotros nos aseguremos que todo ex detenido que sale tiene una oportunidad de laburo dentro de las cooperativas de liberados. Y que esa va a ser la única forma de bajar la reincidencia. Que no hay otra manera. [...] Queremos una mesa de laburo, que podamos entre todas las cooperativas, ir teniendo que proyectar todo este laburo a política de Estado. Porque si no fracasa. Fracasa en qué sentido: no solamente fracasa porque nosotros no vamos a tener laburo, sino fracasamos nosotros porque no pudimos hacer que este problema tan grande que es el tema de la gente que sale en libertad y que anda rondando por todos lados, no sea tomado como política de Estado. Porque es un problema de la sociedad, un problema muy grande de la sociedad el tema de la delincuencia (Araña, comunicación personal). 
Retomamos una parte extensa del testimonio de Araña con el fin de dimensionar la profundidad con la que los y las protagonistas construyen la organización. Así, las cooperativas constituyen una importante dimensión de la experiencia organizativa, vinculada con el derecho al trabajo, pero sin agotarse en él. El horizonte del colectivo de liberados se vincula con la intervención a través de las políticas públicas, apuntando a la transformación de la realidad del sector a partir de sus propias vivencias:

[...] si esto lo hubiese hecho hace diez años atrás hoy estarían sentados mis dos hermanos acá. Pero por la delincuencia hoy no están. Yo lo tomé un poco más personal porque yo tuve muchas pérdidas. $Y$ hoy tengo la vida que siempre quise (Hueso, comunicación personal).

Los testimonios de los y las protagonistas nos indican que las cooperativas de liberados y liberadas sientan las bases para que sus integrantes construyan proyectos personales/colectivos autónomos a partir del sentido de pertenencia y de la cultura del trabajo como sentido organizador. En sus dinámicas organizacionales se producen movimientos subjetivos a partir del encuentro entre las lógicas individualistas que priman en la cárcel, y las lógicas de compañerismo y solidaridad que promueven el cooperativismo y la economía popular, produciendo nuevas subjetividades. De esta manera, la experiencia de transitar la salida en libertad, contenidos y contenidas en una organización, en contraposición al intento de integrarse en la trama comunitaria de manera individual, tiene un fuerte impacto en las trayectorias de vida de los y las liberadas.

\section{Notas}

(1) Se trata de un subsidio económico equivalente al 50\% del salario mínimo, vital y móvil.

\section{Bibliografía}

Acotto, L. (2003). Las organizaciones de la sociedad civil: un camino para la construcción de ciudadanía. Buenos Aires, Argentina: Espacio.

Goffman, E. (2010). Estigma: La identidad deteriorada. Buenos Aires, Argentina: Amorrortu editores. 
Kessler, G. (2010). Delito, sentimiento de seguridad y políticas públicas. VI Jornadas de Sociología de la UNLP, 9 y 10 de diciembre, La Plata, Argentina.

Malacalza, L. (2012). Mujeres en prisión: las violencias invisibilizadas. Question, 1(36), Primavera, pp. 59-66.

Míguez, D. (2008). Delito y cultura. Los códigos de la ilegalidad en la juventud marginal urbana. Buenos Aires, Argentina: Editorial Biblos.

Pocai, S. (2014). Políticas Públicas de seguridad: Un estudio de caso: el Patronato de Liberados Bonaerense. (Trabajo final de grado). Facultad de Humanidades y Ciencias de la Educación, Universidad Nacional de La Plata.

Reguillo, R. (1994). Movimientos sociales y comunicación. Una perspectiva gramsciana. En Reguillo, R. (Ed.). Comunicación, sentido y vida cotidiana. Jalisco, México: ITESO. Tlaquepaque.

Reguillo, R. (2003). Los miedos: sus laberintos, sus monstruos, sus conjuros. Una lectura socioantropológica. Etnografías contemporáneas, 2(2), pp. 45-72.

Viegas Barriga, F. (2009). La reja en la cabeza. Etnografía, representaciones, experiencias y mediaciones en torno al impacto de la cárcel en personas con libertad ambulatoria. Question, 1(23), primavera.

Viegas Barriga, F. (2012a). Desorientados. Modos de circulación y apropiación espacial de liberados de cárceles bonaerenses (2009-2012). Question, 1(36), Primavera.

Viegas Barriga, F. (2012b). La penalidad (in corpo)rada. Selectividad y criminalización desde la comunicación/cultura. En Echeverría, M. y Vestfrid, P. (Coord.). (2012). Aprender a investigar. Recorridos iniciales en comunicación. La Plata, Argentina: Ediciones EPC.

\section{Informes}

Sistema Nacional de Estadística de la Ejecución de la Pena (SNEEP). (2016). Informe anual 2016. Ministerio de Justicia y Derechos Humanos de la Nación. 